\title{
NORMAL CONCENTRATIONS OF SOME TRACE METALS IN HUMAN URINE: CHANGES PRODUCED BY ETHYLENEDIAMINETETRAACETATE *
}

\author{
By H. MITCHELL PERRY, JR. $\dagger$ AND ELIZABETH F. PERRY \\ (From the Hypertension Division, Department of Internal Medicine, Washington University \\ School of Medicine and Barnes Hospital, Saint Louis, Mo.)
}

(Submitted for publication January 12, 1959, accepted April 30, 1959)

Interest in the biologic role of trace elements prompted an investigation of their renal excretion. Preliminary qualitative analysis revealed that except for cobalt the entire first transition series of metals, namely, titanium, vanadium, chromium, manganese, iron, nickel and copper, were detectable in most human urines. In addition the heavier transition metals, molybdenum and silver, as well as the related metals, zinc, cadmium, tin and lead, were ordinarily present. A method was evolved by which the urinary concentrations of such metals could be quantitatively estimated. The procedure included initial chemical concentration followed by spectrographic analysis. Contamination was minimized by careful preparation of equipment and reagents. Since extraneous iron and copper were particularly difficult to avoid and since these two metals had frequently been studied by other techniques, no attempt was made to measure them spectrographically. The exclusion of significant positive contamination, the demonstration that the low renal excretion of cobalt permitted its use as an internal standard, and the determination of standard working curves and recovery data for each metal constituted the control data for the assay procedure. Estimations were less satisfactory for chromium and titanium than for the remaining nine metals.

Collection and assay of 24 hour urines were performed in a standard manner. Such urines from normal persons served to indicate both the mean level and the variability of excretion for the nine trace metals which could be satisfactorily estimated. Daily differences in the renal excretion of metal as well as the effects produced by

\footnotetext{
* Supported by grants-in-aid from the National Heart Institute of the United States Public Health Service, the American Heart Association, the Life Insurance Medical Research Fund and Abbott Laboratories.

$\dagger$ Established Investigator, American Heart Association.
}

extremes of urinary volume and $\mathrm{pH}$ were determined for 24 hour urines from one normal individual. A brief preliminary study was made of the metallic spectrum in single specimens of urine from hospitalized African natives. Finally, metal concentration was measured in consecutive 24 hour urines from hypercholesterolemic patients before, during and after the parenteral administration of the chelating agent, disodium calcium ethylenediaminetetraacetate, which had been observed to lower the level of cholesterol in human plasma (1).

\section{METHODS}

Preliminary qualitative urinalysis. In order to select the metals to be assayed, 40 single urine specimens from different subjects were analyzed qualitatively. Half of the samples were obtained from normal individuals and half from hospitalized patients with atherosclerosis and hypertension. The urines were evaporated to approximately one-twentieth of their original volume, after which most of the organic material was oxidized with hydrogen peroxide. The residues were then dried, mixed with an approximately equal amount of graphite, and burned to completion in a direct current arc. The photographed spectra were examined, several levels of intensity being provided for each sample by use of a rotating step-sector disc.

As was expected, magnesium and calcium were always found, strontium was present in all except seven samples, but barium was not identified. Aluminum was also invariably found. Boron was excreted by one patient, a 63 year old hypertensive female whose urine contained boron both before and after she was treated with hydralazine. Every element of the first transition series from titanium to copper was identified in more than one sample, although cobalt was present only twice and then in barely detectable traces. Molybdenum and silver were the only heavier transition elements found. Zinc, cadmium, tin and lead were the only additional nontransition metals detected aside from the alkali metals.

Chemical concentration. A homogeneous $200 \mathrm{ml}$. aliquot of each 24 hour urine sample was measured into a $400 \mathrm{ml}$. glass Berzelius beaker containing a glass stirring 
rod and glass beads. All glassware used in the analysis was rendered metal-free by special cleaning to be described. Approximately $10 \mathrm{ml}$. of redistilled concentrated nitric acid was added to the beaker which was then covered with a watch glass. The mixture was boiled cautiously for several hours until its volume was reduced to about $10 \mathrm{ml}$. An additional $20 \mathrm{ml}$. of the acid was carefully added, and the mixture was again boiled to a volume of $10 \mathrm{ml}$. If the solution remained dark, 10 to $20 \mathrm{ml}$. more of the acid was added to complete the oxidation of organic matter. Except for urines with considerable amounts of protein, a total of $50 \mathrm{ml}$. of redistilled concentrated nitric acid was adequate to produce $10 \mathrm{ml}$. of a clear amber solution. A maximum of $50 \mathrm{ml}$. of redistilled concentrated hydrochloric acid was then cautiously added, in several portions, to the hot nitrated residue in order to reduce the excess nitric acid and to convert the nitrates to chlorides. After each addition the resulting solution was once again carefully boiled down to a volume of $10 \mathrm{ml}$. When reduction was complete a very pale yellow color replaced the original red or orange color. The cool solution was diluted to $150 \mathrm{ml}$. with redistilled metal-free zeater. An internal standard consisting of $1.00 \mathrm{ml}$. of 0.00200 per cent aqueous cobalt was added. As a carrier for precipitataion and as a matrix for ignition, $5.0 \mathrm{ml}$. of 0.5 per cent aqueous aluminum oxide was also added.

The remainder of the chemical concentration was as described by Mitchell and Scott under the heading "Precipitation by 8 -hydroxyquinoline + tannic acid + thionalide" (2). Briefly, $10 \mathrm{ml}$. of 5 per cent 8 -hydroxyquinoline in 2 normal distilled acetic acid was added, and the $\mathrm{pH}$ of the solution was adjusted to $1.90 \pm 0.05$ by the dropwise addition of approximately 8 normal purified ammonium hydroxide. After an hour, $30 \mathrm{ml}$. of purified 2 normal ammonium acetate was added, bringing the $\mathrm{pH}$ to approximately 4.8. Next, $2.0 \mathrm{ml}$. of 10 per cent aqueous tannic acid and $2.0 \mathrm{ml}$. of 1 per cent thionalide in glacial acetic acid were added. The $\mathrm{pH}$ then was readjusted to $5.10 \pm 0.05$ by the addition of as much as $30 \mathrm{ml}$. of approximately normal purified ammonium hydroxide, after which the mixture was allowed to stand for 24 to 48 hours. Finally the precipitate was collected on $11 \mathrm{~cm}$. Whatman No. 54 filter paper and washed several times with redistilled metal-free water.

Spectrographic analysis. The filter paper containing the washed precipitate was packed in a covered metal-free platinum crucible and placed in a muffle furnace. The temperature of the furnace was raised to just above $100^{\circ}$ C. and kept there until the paper and the precipitate were nearly dry. The temperature was then increased to 420 to $425^{\circ} \mathrm{C}$. and kept there for no more than six hours, after which time the filter paper was virtually gone. Because of the volatility of cadmium, great care was taken to keep the time and temperature of heating to a minimum. After cooling, the residue was ground in a metal-free agate mortar with an approximately equal portion of graphite powerder. Approximately $10 \mathrm{mg}$. of the ash and graphite sample was placed in the crater of a sample electrode which was made the cathode in an 8 ampere direct current arc. The electrode gap was made $5 \mathrm{~mm}$. and the region of the arc $1 \mathrm{~mm}$. above the cathode was focused on the collimeter of an ARL 1.5 M. grating spectograph with a slit width of $50 \mu$. During the entire 25 seconds of burning, the spectrum from 2,250 to $4,500 \AA$ was photographed on Eastman SA No. 1 film, each roll of which was calibrated by the two-step method. The film was developed for three minutes in D-19 developer, immersed for 15 seconds in 3 per cent acetic acid, fixed for seven minutes in Kodak Acid Fixer, and washed for 10 minutes in running water, all at $20^{\circ} \mathrm{C}$. The percentage transmissions for each of the lines indicated in Table $I$ and of the chromium line at $4,254.3 \AA$ were determined on a densitometer, and after correction for background the values obtained were converted to intensity ratios with respect to the $3,334.1 \AA$ cobalt line. In order to increase accuracy, each sample of ash and graphite was burned in duplicate.

Equipment and reagents. Metal-frec equipment was prepared by rendering it visibly clean with detergent and allowing it to stand overnight in equal parts of concentrated nitric and sulfuric acids. Each piece was then successively rinsed a half-dozen times in tap water, in distilled water, and in the redistilled metal-free water described below, after which it was allowed to dry in air under a Parafilm cover. All glass and polyethylene equipment which came in contact with the original urine, with aliquots at any stage in the analytic procedure, or with metalfree reagents was so treated to render it metal-free. All reagents and urines were stored in polyethylene containers. All distilling apparatus was made entirely of glass.

Redistilled metal-free water was prepared by putting doubly distilled water through an ion exchange resin. All water used in the preparation of reagents was purified in this manner and had a conductivity of less than 1.0 micromho.

Redistilled concentrated nitric acid and redistilled concentrated hydrochloric acid were prepared by twice distilling concentrated analytic reagent grade acid. Approximately 15 and 9 normal acids were obtained, respectively. Enough nitric acid to perform a large number of analyses was prepared and pooled so that it would not prove a source of short term variation.

0.00200 per cent aqueous cobalt was prepared with reagent grade cobaltous chloride. The final solution contained $20 \mathrm{mg}$. of cobalt per $\mathrm{L}$. so that $1.00 \mathrm{ml}$. in $200 \mathrm{ml}$. of urine yielded a concentration of 100 parts of cobalt per billion parts of urine.

Purified ammonium hydroxide with a concentration approximating 8 normal was prepared by distilling ammonia from reagent grade ammonium hydroxide and collecting it in water.

0.5 per cent aqueous purified aluminum oxide was prepared by precipitating aluminum hydroxide from an aqueous solution of reagent grade (chromium-free) aluminum chloride with purified ammonium hydroxide. The precipitate was washed and then dissolved in warm redistilled concentrated hydrochloric acid. The resulting solution 


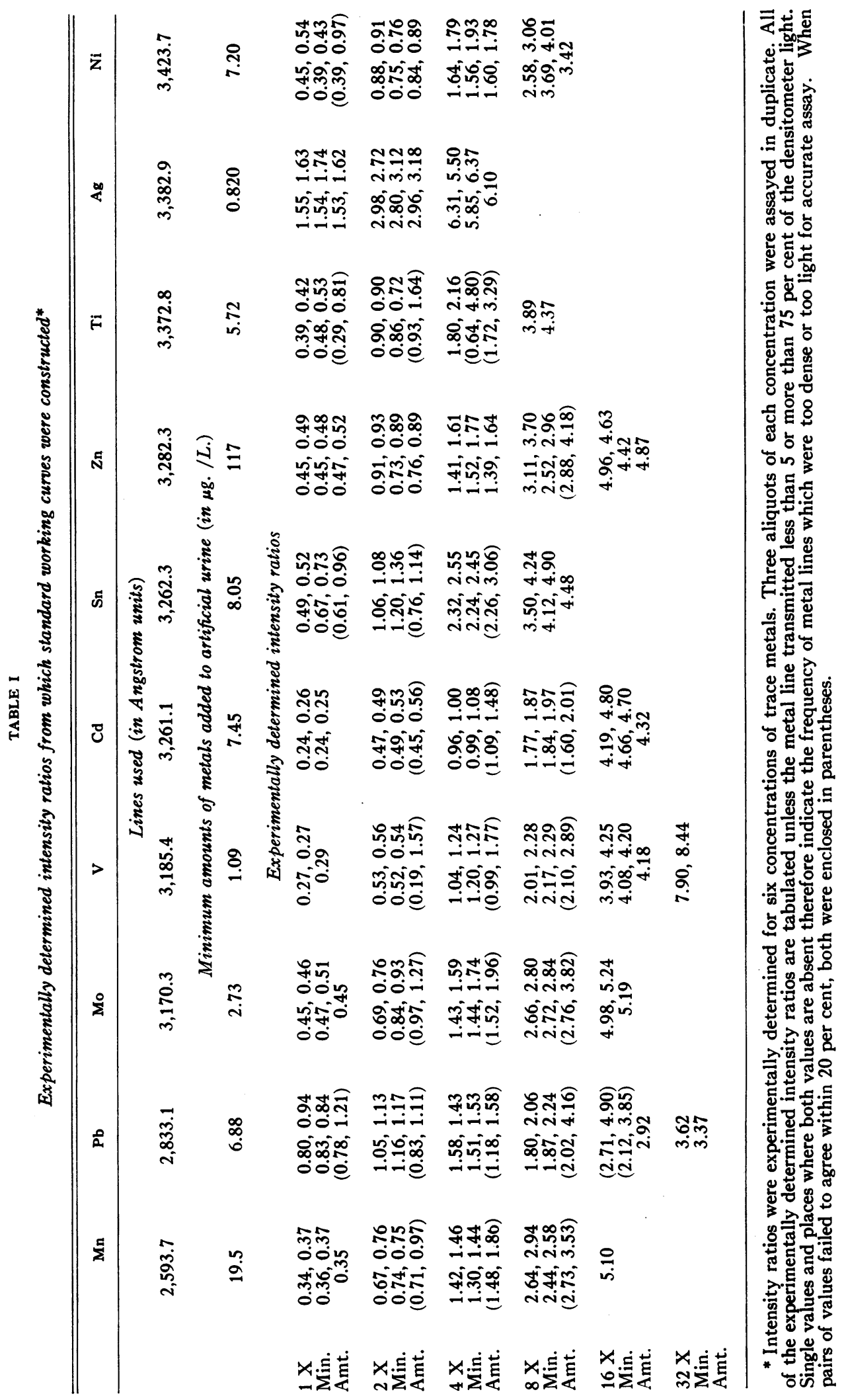


was extracted thrice with reagent grade diethyl ether, heated to remove excess ether, and suitably diluted.

Distilled glacial acetic acid was prepared by distilling reagent grade glacial acetic acid (Mallinckrodt).

5 per cent 8-hydroxyquinoline in 2 normal distilled acetic acid, 10 per cent aqueous tannic acid, and 1 per cent thionalide in distilled glacial acetic acid were prepared weekly with reagent grade 8-hydroxyquinoline (Mallinckrodt), reagent grade tannic acid (Eimer and Amend 0.000 per cent heavy metal as lead), and high purity thionalide (Merck), respectively.

Purified 2 normal ammonium acetate was prepared by titrating distilled glacial acetic acid with purified ammonium hydroxide to yield a solution of $\mathrm{pH} 7$.

Graphite powder was Ultra Purity Graphite Powder UCT-2-200 obtained from United Carbon Products Company, Inc., Bay City, Mich.

Counter electrodes were Preformed Ultra Purity Graphite Counter Electrodes No. $100 \mathrm{U}$ made by United Carbon Products Company.

Sample electrodes were made from one-fourth by 12 inch U-2 Hi Purity Graphite Rods obtained from United Carbon Products Company. An ellipsoidal depression $2 \mathrm{~mm}$. deep and $6 \mathrm{~mm}$. in diameter was cut in one end of a $40 \mathrm{~mm}$. section of the rod.

Control data for assay. In order to be certain that the reagents and equipment introduced no positive contamination, an artificial urine without organic components was prepared. Redistilled metal-free water was made 0.10 mo- lar with respect to sodium chloride, 0.050 molar with respect to potassium chloride, and 0.010 molar with respect to both magnesium and calcium chlorides. To four separate $200 \mathrm{ml}$. aliquots of the artificial urine, $50 \mathrm{ml}$. of redistilled concentrated nitric acid and then $50 \mathrm{ml}$. of redistilled concentrated hydrochloric acid were added. Thereafter each of the four samples was assayed for manganese, lead, molybdenum, vanadium, cadmium, tin, zinc, titanium, silver, nickel and chromium, in the manner described. Using the lines indicated in Table $I$ for the first 10 metals and the chromium line at $4,254.3 \AA$, no detectable trace of any of these metals was found.

In order to confirm the suitability of cobalt as an internal standard, single urine samples of more than 200 $\mathrm{ml}$. from 12 apparently healthy individuals were collected directly into metal-free containers. Twelve hospital patients who were receiving no drugs and who had a variety of diseases including hypertension, atherosclerosis, cirrhosis, nephrosis, diabetes, idiopathic hypercholesterolemia and lead poisoning furnished similar specimens. An additional 12 specimens were obtained from patients with the same diseases during a period of intravenous disodium calcium ethylenediaminetetraacetate therapy. Except that no internal standard was added, all 36 specimens were assayed in the manner described. No trace of the cobalt line at $3,334.1 \AA$ was found.

In order to obtain standard working curves from which the metal concentrations in actual urines could be determined, known quantities of 11 metals were added to the previously mentioned artificial urine. Under the head-

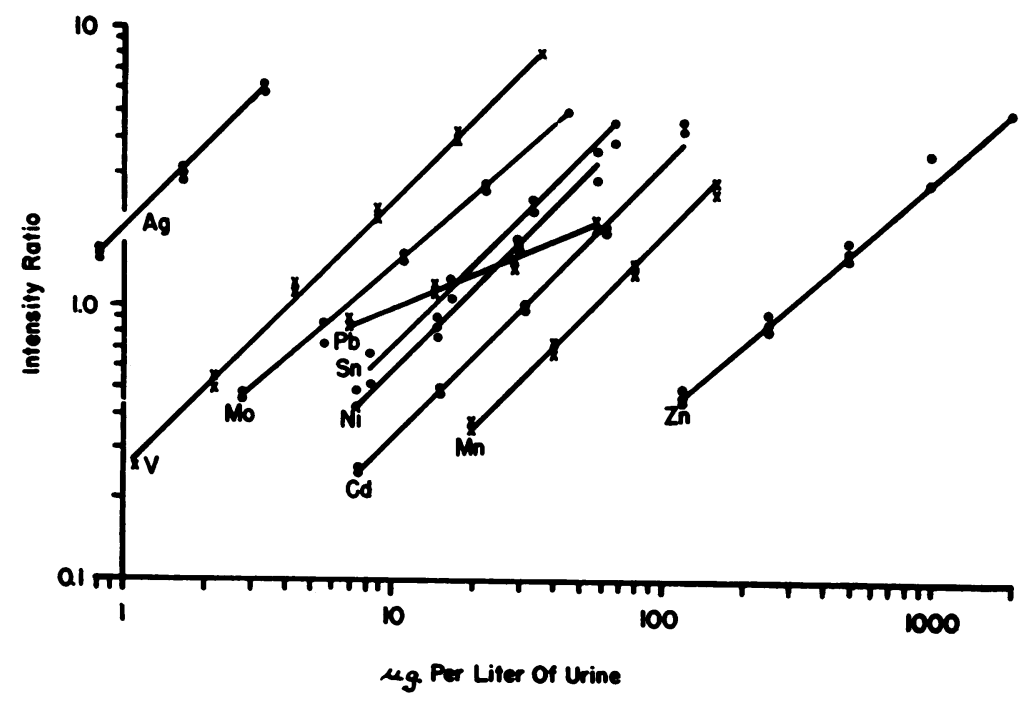

Fig. 1. Standard Working Curves for Converting Intensity Ratio to METAL CONCENTRATION

The curves were plotted from the data given in Table I. Each point is the average of a pair of values which agreed to within 20 per cent. Zinc, nickel and molybdenum points are indicated by solid dots. Manganese, lead and vanadium points are indicated by crosses. Cadmium, tin and silver points are indicated by open circles. No curve is given for titanium since the data were considered inadequate. 
TABLE II

Reproducibility of metal assay in human urine

\begin{tabular}{|c|c|c|c|c|c|c|c|c|c|c|}
\hline & $\mathrm{Mn}$ & $\mathrm{Pb}$ & Mo & $\mathrm{v}$ & $\mathrm{Cd}$ & Sn & $\mathrm{Zn}$ & $\mathrm{Ti}$ & Ag & $\mathrm{Ni}$ \\
\hline \multicolumn{11}{|c|}{ Mean concentrations of metal in pool of normal urine on duplicate analyses $(\mu \mathrm{g} . / L)}$. \\
\hline & 24.0 & 9.81 & 21.6 & 2.70 & 10.7 & 9.17 & 120 & 10.2 & 0.87 & 14.8 \\
\hline \multicolumn{11}{|c|}{ Metal added to urine pool $(\mu \mathrm{g} . / L)}$. \\
\hline & 39.0 & 13.8 & 5.46 & 2.18 & 14.9 & 8.05 & 117 & 11.4 & 1.64 & 7.20 \\
\hline \multicolumn{11}{|c|}{ Mean for 10 replicate assays after the above amounts of metal were added to urine pool $(\mu \mathrm{g} . / L)}$. \\
\hline S.E.M.* & $\begin{array}{r}58.0 \\
1.7\end{array}$ & $\begin{array}{r}25.5 \\
1.0\end{array}$ & $\begin{array}{r}26.8 \\
1.0\end{array}$ & $\begin{array}{l}4.51 \\
0.41\end{array}$ & $\begin{array}{c}26.2 \\
0.51\end{array}$ & $\begin{array}{c}18.2 \\
0.77\end{array}$ & $\begin{array}{r}241 \\
4.3\end{array}$ & $\begin{array}{r}20.6 \\
1.7\end{array}$ & $\begin{array}{l}2.56 \\
0.044\end{array}$ & $\begin{array}{c}22.5 \\
0.61\end{array}$ \\
\hline
\end{tabular}

* Standard errors of the means.

ing, minimum amounts of metals added, Table I indicates 10 of the metals and the concentration of each that was used. These metals were added as the chlorides except for vanadyl sulfate, ammonium molybdate, silver nitrate and lead acetate. In addition, $5.73 \mu \mathrm{g}$. of chromium per L. was added; however, the assay for chromium was unsatisfactory and no quantitative data are given for this metal. Three identical $200 \mathrm{ml}$. aliquots of the artificial urine with the added metals were assayed in duplicate as described. The experimentally determined pairs of intensity ratios and their corresponding metal concentrations are given in Table I. Additional artificial urines with the previously mentioned concentrations of alkali metals and alkaline earths were made two, four, eight, 16, and 32 times as concentrated with respect to each of the 11 transition and related metals. Three $200 \mathrm{ml}$. aliquots of each of these solutions were assayed. The results are given in Table I. All of the values are tabulated except when the metal line transmitted less than 5 or more than 75 per cent of the densitometer light. Those pairs of values which did not agree within 20 per cent have been enclosed in parentheses, and neither they nor the single values were used in constructing the standard working curves, which comprise Figure 1. At least eight pairs of values were available for the standard working curve of each metal, except titanium which was therefore omitted from the figure. All of the standard working curves approximated straight lines over the ranges examined. All also closely approached the expected unit slope, except lead which deviated markedly and zinc and molybdenum which deviated slightly therefrom.

In order to determine the accuracy and reproducibility of the assay, urine was collected directly into a large metal-free polyethylene bottle by several apparently normal laboratory workers. An aliquot was analyzed and found to contain no detectable cobalt. The mean concentration of each of the 10 metals, including titanium, was determined by the method outlined. The results of the initial duplicate assay are listed at the top of Table II. Below are tabulated the known amounts of each metal which were then added to the pool. After the additions, 10 separate $200 \mathrm{ml}$. aliquots were assayed. The experimentally determined mean metal concentration after the additions and the standard error of that mean are indicated for each metal. The coefficients of variation for the 10 replicate assays were calculated from these data and were found to vary from 5 to 6 per cent for cadmium, zinc and silver, to 25 to 30 per cent for vanadium and titanium.

Collection and assay of 24 hour urines. With precautions to avoid contamination, 24 hour urine samples were collected directly into wide-mouthed, metal-free gallon jars to which no preservative had been added. Immediately after additions, the jars were carefully covered with Parafilm ${ }^{\circledR}$. No funnels were used. As soon as 24 hour collections had been completed, homogeneous $600 \mathrm{ml}$. aliquots were transferred to metal-frce polyethylene containers for storage at $2^{\circ} \mathrm{C}$. until analysis. The volume of the remaining urine was measured, its specific gravity and $\mathrm{pH}$ were determined, and a quantitative estimate of its protein concentration was made with Esbach's picric acid reagent.

Despite distillation, nitric acid remained the most likely source of positive contamination. Therefore a single pooled batch of the acid was used for all urines from the normal Americans. A second batch was used for all urines from four of the hypercholesterolemic patients and a third batch for urines from the remaining patients. Each of these batches of acid was made and analyzed as previously described; no $50 \mathrm{ml}$. aliquot was found to contain any of the nine elements considered here.

A total of 144 urines were each assayed for nine metals ; thus, 1,296 pairs of intensity ratios were determined. Each pair of ratios was averaged and then converted to micrograms of metal per liter of urine. In 88 instances the conversion required extrapolation since the averaged intensity ratio exceeded the range covered by the appropriate standard working curve. Extrapolation assumed continued linearity of the standard working curves and was only permitted when the per cent transmission of the lines of both the internal standard and the element in question were between 5 and 75 per cent. Extrapolated values cannot be considered absolute, but they suggest relative concentrations. No extrapolation was needed for vanadium, cadmium or tin; and it was only necessary once for manganese and once for silver. One of 
the normal Americans and seven of the hospitalized Africans had more urinary nickel, and four of each group had more urinary molybdenum, than could be assayed without extrapolation. Although the normal zinc excretion was confined to the range covered by the standard working curve, the zincuria during the intravenous administration of disodium calcium ethylenediaminetetraacetate required extrapolation for 42 of 50 urines. It was the lead assay which was the most disturbing, however. The two unpaired intensity ratios for $220 \mu \mathrm{g}$. lead per L. (Table I) suggest that the standard working curve remained linear at least to that concentration. Two urines from normal Americans and 26 urines from seven of the eight hypercholesterolemic patients required extrapolation beyond this extension of the standard working curve for lead.

Although quantitative data on the excretion of titanium and chromium are not cited, intensity ratios for the 3,372.8 $\AA$ titanium line and for the 4,254.3 $\AA$ chromium line suggested the approximate concentrations of these two metals. The intensity ratio was also determined for the cadmium line at $2,288.0 \AA$ because it was about five times as sensitive as the line at $3,261.1 \AA$, but reproducibility was poor.

\section{MATERIAL}

One 24-hour urine specimen was collected by each of 24 apparently normal individuals. Ten were Negroes, of whom six were female. Among the 14 non-Negroes, four were female; two of the four were in the last trimester of pregnancy. The ages ranged from four to 69 years with two being in the first, two in the second, nine in the third, six in the fourth, one in the fifth, two in the sixth, and two in the seventh decade of life. To minimize environmental differences the sexagenarians were the grandfathers of the two youngest children, both of whom were boys. Nine individuals were laboratory workers, seven were other professional people, five were students, and three were housewives. Each continued to eat his regular diet and to continue his usual daily activities during the collection period. All were working and none was hypertensive. Each urine was examined for proteinuria, but none was found. The collected urines were individually assayed for metals as described.

Six consecutive 24 hour urine specimens were collected by one normal 24 year old white male physician while he was eating his regular diet and working in the laboratory. He collected six more specimens under similar conditions at various other times. The interval between the first and last of these collections exceeded two years. The same individual collected 12 additional 24 hour urine specimens under conditions designed to produce acidic, basic, concentrated and dilute urines. Four consecutive 24 hour urine specimens were collected during a four day period when $12 \mathrm{Gm}$. of ammonium chloride was ingested daily. Similar collections were made during a four day period when $12 \mathrm{Gm}$. of sodium bicarbonate was ingested daily. A pair of consecutive collections was obtained during a two day period of restricted fluid in- take. Similar collections were made during a two day period when fluids were forced. In none of the 24 specimens collected by this individual was protein demonstrated.

In Usumbura, Ruanda-Urundi, Africa, single urine specimens of more than $100 \mathrm{ml}$. were collected directly into wide-mouthed, metal-free, 6 ounce polyethylene bottles. The 12 subjects were all hospitalized normotensive natives between the ages of 17 and 34 years. Half were male. None was more than superficially exposed to Western civilization. The major diagnoses were idiopathic epilepsy and unexplained anemia in three each, parasitic infestation in two, and bacterial pneumonia, mitral disease, tuberculous peritonitis, and bronchial asthma in one each. The urines were assayed as described except that 100 rather than $200 \mathrm{ml}$. aliquots were used. Since the full amount of internal standard was added, the concentration of cobalt was relatively high. An assay was considered unsatisfactory, and therefore repeated, unless the transmission of the internal standard line was less than 40 rather than 75 per cent.

Two to four consecutive 24 hour urine specimens were collected directly into metal-free gallon bottles by eight patients with hypercholesterolemia. Over an approximately three hour period during the next day, seven of the patients received $1.0 \mathrm{Gm}$. of intravenous disodium calcium ethylenediaminetetraacetate $\left(\mathrm{Na}_{2} \mathrm{CaEDTA}\right)$ dissolved in $500 \mathrm{ml}$. of 5 per cent glucose in water. On the subsequent three to nine days, each of these seven patients received $3.0 \mathrm{Gm}$. of $\mathrm{Na}_{2} \mathrm{CaEDTA}$ given in the same manner. The eighth patient received $3.0 \mathrm{Gm}$. of $\mathrm{Na}_{2} \mathrm{CaEDTA}$ for two days and $4.0 \mathrm{Gm}$. on the third day as described (3). During the entire period of chelate administration and in four cases for one or two days thereafter, consecutive 24 hour urine specimens continued to be collected in metal-free bottles. The patients ranged in age from 21 to 63 years. Three were women and one was a Negro. None was on a diet, nor was any receiving other drugs. The primary diagnosis of five was atherosclerosis with objective evidence of involvement of the coronary arteries; the three other major diagnoses were lead poisoning, pseudobulbar palsy and nephrosis. None had hypertension. Only the nephrotic patient had proteinuria; his urine contained from 1.6 to $3.2 \mathrm{Gm}$. of protein per L. (3). Before chelate therapy the concentration of cholesterol was measured in the plasma of each patient; it ranged from 265 to $460 \mathrm{mg}$. per $100 \mathrm{ml}$. At least one subsequent level was obtained for each patient while he was receiving $\mathrm{Na}_{2} \mathrm{CaEDTA}$. For three patients levels were followed daily before, during and after $\mathrm{Na}_{2} \mathrm{CaEDTA}$ administration. The collected urines were assayed as described.

\section{RESULTS}

Part I of Table III lists the mean concentrations of nine metals in the 24 hour urines of 24 normal adults. The standard error of the mean, the range of concentrations, and the number of samples 
TABLE III

Human excretion of nine metals (in $\mu g . /$ L. of urine)*

\begin{tabular}{|c|c|c|c|c|c|c|c|c|c|}
\hline & $\mathbf{Z n}$ & Cd & $\mathbf{M n}$ & $\mathbf{P b}$ & $\mathrm{v}$ & Mo & $\mathrm{Ni}$ & Ag & Sn \\
\hline \multicolumn{10}{|c|}{ Part I. Single 24 hour specimens from 24 normal Americans } \\
\hline $\begin{array}{l}\text { Mean of } 24 \text { specimens } \\
\text { Standard error of the mean } \\
\text { Maximum } \\
\text { Minimum } \\
\text { Number too dilute for accurate assay }\end{array}$ & $\begin{array}{c}318 \\
31.9 \\
740 \\
82 \\
0\end{array}$ & $\begin{array}{l}<12.7 \\
1.20 \\
22 \\
<7.0 \\
7\end{array}$ & $\begin{array}{l}<26.7 \\
2.91 \\
66 \\
<12 \\
6\end{array}$ & $\begin{array}{c}120 \\
35.5 \\
760 \\
5.0 \\
0\end{array}$ & $\begin{array}{l}<6.12 \\
1.55 \\
22 \\
<1.0 \\
10\end{array}$ & $\begin{array}{c}40.8 \\
4.32 \\
150 \\
12 \\
0\end{array}$ & $\begin{array}{l}20.1 \\
2.59 \\
70 \\
10 \\
0\end{array}$ & $\begin{array}{l}1.61 \\
0.15 \\
3.8 \\
0.42 \\
0\end{array}$ & $\begin{array}{l}16.6 \\
1.84 \\
40 \\
3.0 \\
0\end{array}$ \\
\hline $\begin{array}{l}\text { Mean of } 10 \text { females } \\
\text { Mean of } 14 \text { males } \\
\text { Mean of } 10 \text { Negroes } \\
\text { Mean of } 14 \text { non-Negroes } \\
\text { Mean of } 2 \text { boys of } 4 \text { and } 6 \text { years } \\
\text { Mean of } 2 \text { men of } 64 \text { and } 69 \text { years }\end{array}$ & $\begin{array}{l}329 \\
310 \\
335 \\
307 \\
333 \\
233\end{array}$ & $\begin{array}{r}<10.9^{5} \\
<13.9^{1} \\
<15.3^{2} \\
<11.1^{4} \\
9.75 \\
19.25\end{array}$ & $\begin{aligned}<23.4^{2} \\
<29.1^{3} \\
<30.3^{3} \\
<25.1^{2} \\
\quad 24.5 \\
21.8\end{aligned}$ & $\begin{array}{c}110 \\
126 \\
149 \\
97.2 \\
43.3 \\
97.0\end{array}$ & $\begin{array}{l}<3.98^{4} \\
<7.66^{5} \\
<6.85^{7} \\
<5.75^{8} \\
3.05 \\
16.8\end{array}$ & $\begin{array}{l}32.3 \\
46.9 \\
44.7 \\
29.0 \\
33.5 \\
39.5\end{array}$ & $\begin{array}{l}16.6 \\
22.6 \\
23.4 \\
18.1 \\
17.0 \\
20.0\end{array}$ & $\begin{array}{l}1.51 \\
1.67 \\
1.50 \\
1.67 \\
1.18 \\
0.820\end{array}$ & $\begin{array}{r}16.4 \\
16.8 \\
17.9 \\
15.8 \\
7.70 \\
11.75\end{array}$ \\
\hline \multicolumn{10}{|c|}{ Part II. Twenty-four 24 hour specimens from one normal white American male of 24 years } \\
\hline $\begin{array}{l}\text { Mean of } 12 \text { "ordinary" specimens } \\
\text { Standard error of the mean } \\
\text { Maximum } \\
\text { Minimum } \\
\text { Number too dilute for accurate assay }\end{array}$ & $\begin{array}{l}279 \\
16.2 \\
370 \\
170 \\
0\end{array}$ & $\begin{array}{l}12.9 \\
1.10 \\
20 \\
7.3 \\
0\end{array}$ & $\begin{array}{l}20.8 \\
1.77 \\
45 \\
13 \\
0\end{array}$ & $\begin{array}{c}91.1 \\
11.4 \\
160 \\
48 \\
0\end{array}$ & $\begin{array}{l}<4.73 \\
1.19 \\
15 \\
<1.0 \\
3\end{array}$ & $\begin{array}{c}34.7 \\
6.62 \\
110 \\
7.2 \\
0\end{array}$ & $\begin{array}{l}12.7 \\
1.24 \\
22 \\
6.6 \\
0\end{array}$ & $\begin{array}{l}1.45 \\
0.46 \\
2.2 \\
0.78 \\
0\end{array}$ & $\begin{array}{l}16.3 \\
1.42 \\
21 \\
8.8 \\
0\end{array}$ \\
\hline $\begin{array}{l}\text { Mean of } 2 \text { days with } \mathrm{pH} \text { of } 4.5 \\
\text { Mean of } 2 \text { days with } \mathrm{pH} \text { of } 7.8 \\
\text { Mean of } 2 \text { days with volume of } 1,400 \mathrm{ml} \text {. } \\
\text { Mean of } 2 \text { days with volume of } 8,425 \mathrm{ml} \text {. }\end{array}$ & $\begin{array}{l}300 \\
215 \\
350 \\
305\end{array}$ & $\begin{array}{l}13.3 \\
18.5 \\
16.9 \\
13.2\end{array}$ & $\begin{array}{l}21.5 \\
19.9 \\
19.8 \\
21.0\end{array}$ & $\begin{array}{r}21.9 \\
43.5 \\
143 \\
75.0\end{array}$ & $\begin{array}{c}7.2 \\
11.9 \\
10.0 \\
1.58\end{array}$ & $\begin{array}{l}8.10 \\
21.5 \\
25.0 \\
10.0\end{array}$ & $\begin{array}{l}10.0 \\
11.0 \\
11.0 \\
11.6\end{array}$ & $\begin{array}{l}0.93 \\
1.05 \\
1.35 \\
1.83\end{array}$ & $\begin{array}{r}9.50 \\
35.0 \\
17.8 \\
7.3\end{array}$ \\
\hline \multicolumn{10}{|c|}{ Part III. Single specimens from 12 hospitalized African patients } \\
\hline $\begin{array}{l}\text { Mean of } 12 \text { hospitalized patients } \\
\text { Standard error of the mean } \\
\text { Maximum } \\
\text { Minimum } \\
\text { Number too dilute for accurate assay }\end{array}$ & $\begin{array}{r}798 \\
113 \\
1,400 \\
70 \\
0\end{array}$ & $\begin{array}{c}<18.8 \\
0.94 \\
33 \\
<14 \\
1\end{array}$ & $\begin{array}{l}<88.4 \\
3.63 \\
560 \\
<30 \\
7\end{array}$ & $\begin{array}{r}38.9 \\
26.2 \\
220 \\
12 \\
0\end{array}$ & $\begin{array}{l}<2.42 \\
0.25 \\
8.8 \\
<1.6 \\
8\end{array}$ & $\begin{array}{c}77.5 \\
24.6 \\
200 \\
12 \\
0\end{array}$ & $\begin{array}{c}180 \\
21.2 \\
500 \\
27 \\
0\end{array}$ & $\begin{array}{l}0.828 \\
0.17 \\
1.8 \\
0.48 \\
0\end{array}$ & $\begin{array}{c}<10.7 \\
1.02 \\
25 \\
<6.0 \\
4\end{array}$ \\
\hline
\end{tabular}

* In order to define the metal excretion as completely as possible, the mean concentration with its standard error and the range of concentration with the number of specimens too dilute for accurate assay are tabulated in each of the three parts of the table. A < preceding a mean value indicates that at least one of the individual values was too small to determine accurately. For instance, the mean cadmium excretion is given as $<12.7 \mu \mathrm{g}$. per L. for the 24 normal Americans. The fifth row of figures indicates that seven of the samples contained less than the minimum accurately measurable amount, approximately 7.0 $\mu \mathrm{g}$. per L. In calculating the mean of $12.7 \mu \mathrm{g}$. all 24 samples were considered, and the maximum value of $7.0 \mu \mathrm{g}$. was assigned to the seven cadmium-poor urines. Obviously the resultant mean is also a maximum value; however, it is smaller and therefore closer to the actual value than the mean of the 17 urines with measurable cadmium. For the female, male, Negro and non-Negro rows in Part I a superscript following a mean value indicates the number of samples too dilute to assay which went into calculation of that particular mean. Thus five of the ten female subjects had less urinary cadmium than could be accurately determined. Except for the Africans such uncertain means are confined to cadmium, manganese and vanadium.

in which a metal was too dilute to assay are also given. The average daily urine volume was 1,410 $\mathrm{ml}$. Part I further compares the metal excretion of females and males, of Negroes and non-Negroes, and of children and old men. The tabulated data suggest no marked sex or race differences. Although not indicated in the table, none of the four white females excreted a measurable amount of vanadium. The urines of the patients in their teens and their fifties did not confirm the suggestive differences between the urines of the boys and their sexagenarian grandfathers with respect to cadmium, vanadium and lead excretion. The urines of the two pregnant women were not remarkable.
Part II of Table III lists the mean concentrations of the same metals in 12 "ordinary" 24 hour specimens from one normal adult. The standard error of the mean, the range of concentrations, and the number of samples in which a metal was too dilute to assay are also tabulated. The average daily urine volume was $1,590 \mathrm{ml}$. No change was evident in excretion pattern over the two years during which collections were made. Part II further compares the metal excretion in acidic and basic urine and in concentrated and dilute urine. On the four days during which ammonium chloride was ingested, urinary $\mathrm{pH}$ 's were 5.7, 5.2, 4.6 and 4.4 , respectively. On the four days during which sodium bicarbonate was ingested, urinary $\mathrm{pH}$ 's 
were $7.1,7.3,7.9$ and 7.7, respectively. Because the effect of the maximum $\mathrm{pH}$ change was sought, only the final two days of each period were included in the table. The urine volumes for these final two day periods were 2,730 and $2,640 \mathrm{ml}$. for the acidic and basic urines, respectively. The 24 hour volumes of the two concentrated urines were 675 and $725 \mathrm{ml}$., their specific gravities were 1.027 and 1.028, and their pH's were 6.0 and 6.1. The 24 hour volumes of the two dilute urines were 4,350 and $4,075 \mathrm{ml}$., their specific gravities were 1.002 and 1.003 , and their $\mathrm{pH}$ 's were 5.8 and 6.2. Changing the urinary $\mathrm{pH}$ or concentration had no evident effect on zinc, cadmium, manganese, nickel or silver excretion which usually differed by no more than 30 per cent from the mean of the same individual's 12 "ordinary" specimens. Possible changes were confined to molybdenum, lead, vanadium and tin. The molybdenum content was between 20 and $50 \mu \mathrm{g}$. per L. of urine in 10 of the 12 routine specimens and in all the basic and concentrated specimens, whereas in the four acidic and the two dilute specimens it was between 7 and $11 \mu \mathrm{g}$. per L. There was less lead in each one of the four acidic urines than in any of the other specimens. Similarly there was more tin in each of the four basic urines than in any of the other specimens. The very large range of vanadium concentrations in the 12 "ordinary" urines made it impossible to evaluate the sixfold difference between the concentrated and dilute urines.

Part III of Table III lists the mean concentrations of the same metals in the urines of 12 hospitalized African Negroes. The standard error of the mean, the range of concentrations, and the number of samples in which a metal was too dilute to assay are also tabulated. Comparing single specimens from sick Africans and 24 hour collections from healthy Americans is difficult. In addition the smaller aliquots of African urine decreased the sensitivity of the method. The ranges of silver, tin, vanadium, lead, molybdenum, and cadmium concentrations were not obviously dissimilar for the Africans and the Americans, despite differences in their mean concentrations. In

TABLE IV

Mean urinary excretion of nine metals for eight patients before, during and after intravenous $\mathrm{Na}_{2} \mathrm{CaEDTA}$ (in $\mu g . / L$. of urine)*

\begin{tabular}{|c|c|c|c|c|c|c|c|c|c|c|c|}
\hline Day & EDTA & No. pts. & $\mathrm{Zn}$ & $\mathrm{Cd}$ & $\mathbf{M n}$ & $\mathbf{P b}$ & $\mathrm{V}$ & Mo & $\mathrm{Ni}$ & Ag & Sn \\
\hline \multicolumn{12}{|c|}{ Part I. Before $\mathrm{Na}_{2} \mathrm{CaEDTA}$ administration } \\
\hline $\begin{array}{l}1 \\
2 \\
3 \\
4\end{array}$ & $\begin{array}{l}\mathbf{0} \\
\mathbf{0} \\
\mathbf{0} \\
\mathbf{0}\end{array}$ & $\begin{array}{l}5 \\
6 \\
8 \\
8 \\
\text { Mear }\end{array}$ & $\begin{array}{l}221 \\
298 \\
259 \\
264 \\
261\end{array}$ & $\begin{array}{l}<13.3^{1} \\
<12.0^{1} \\
<14.4^{2} \\
<12.1^{3} \\
<13.0\end{array}$ & $\begin{array}{l}<12.0^{3} \\
<17.0^{3} \\
<17.4^{4} \\
<14.9^{3} \\
<15.3\end{array}$ & $\begin{array}{r}208 \\
118 \\
210 \\
89 \\
156\end{array}$ & $\begin{array}{r}11.4 \\
12.3 \\
9.9 \\
7.1 \\
10.2\end{array}$ & $\begin{array}{l}19.0 \\
21.4 \\
20.4 \\
23.1 \\
21.0\end{array}$ & $\begin{array}{l}19.1 \\
23.5 \\
15.0 \\
17.0 \\
18.7\end{array}$ & $\begin{array}{l}1.02 \\
1.19 \\
1.12 \\
0.95 \\
1.07\end{array}$ & $\begin{array}{l}22.4 \\
21.4 \\
19.0 \\
19.6 \\
20.6\end{array}$ \\
\hline
\end{tabular}

Part II. During $\mathrm{Na}_{2} \mathrm{CaEDTA}$ administration

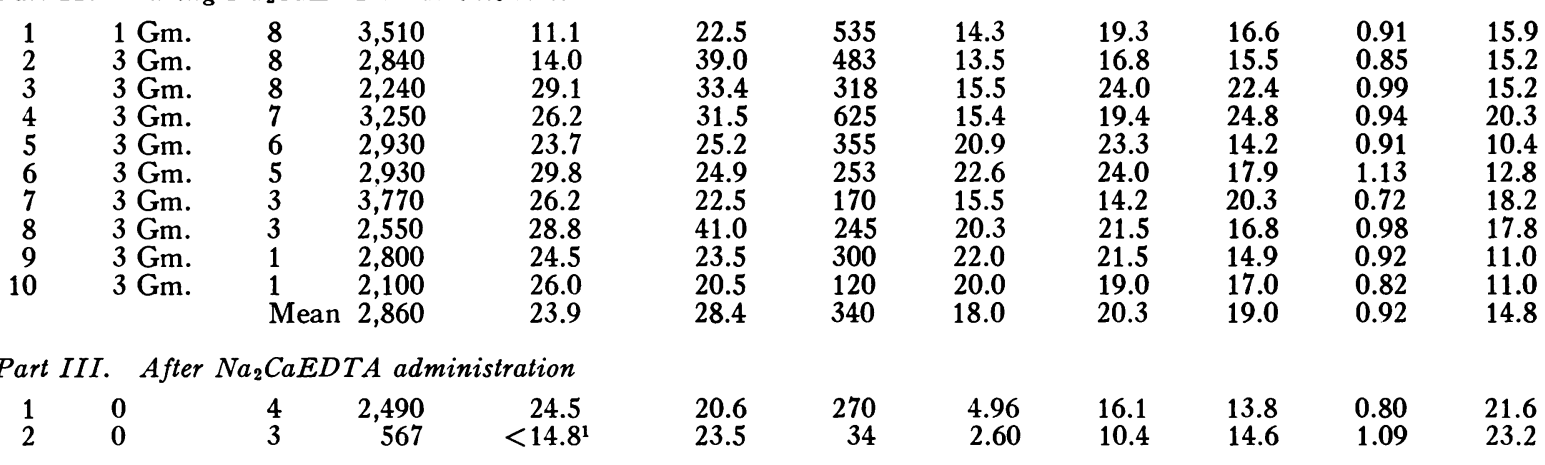

* Urine was collected on every day that $\mathrm{Na}_{2} \mathrm{CaEDTA}$ was given and the results are tabulated for all collections. The fact that there was only one patient for the ninth and tenth day, for instance, indicates that only one patient received $\mathrm{Na}_{2} \mathrm{CaEDTA}$ that long. The nephrotic patient who has already been reported (3) received $3 \mathrm{Gm}$. of $\mathrm{Na}{ }_{2} \mathrm{CaEDTA}$ on the first two days, $4 \mathrm{Gm}$. on the third day, and nothing thereafter. Each of the mean values for cadmium and manganese concentration before $\mathrm{Na}_{2} \mathrm{CaEDTA}$ administration is a maximum value as indicated by the preceding $<$. The superscript indicates the number of samples too dilute to assay. In obtaining the means such dilute samples were assigned their maximum values which approximated $7 \mu \mathrm{g}$. per L. for cadmium and $12 \mu \mathrm{g}$. per L. for manganese. 


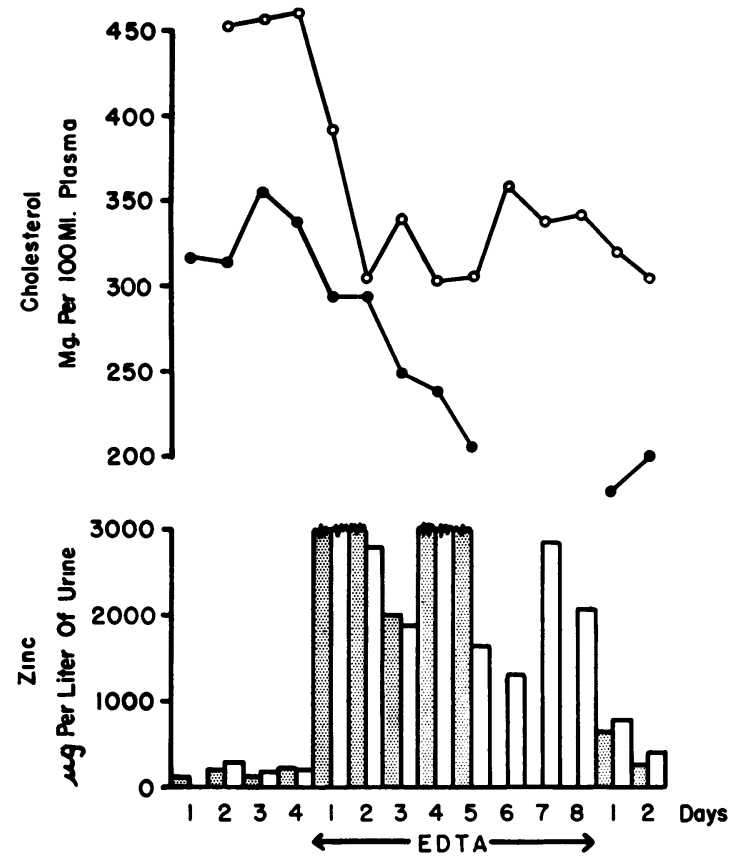

Fig. 2. The Increase in Zincuria and Concurrent Decrease in Plasma Cholesterol for Two AtheroSCLEROTIC WOMEN

Daily cholesterol and zinc assays were made for both patients before, during and after administration of $\mathrm{Na}_{2} \mathrm{CaEDTA}$. The bar graph indicates the renal excretion of zinc, and the line graph indicates the level of plasma cholesterol. Stippled bars and solid dots represent one patient, while open bars and hollow dots represent the other. Four pre- $\mathrm{Na}_{2} \mathrm{CaEDTA}$ values are given for the former and three for the latter. The former received $\mathrm{Na}_{2} \mathrm{CaEDTA}$ for only five days, whereas the latter received it for eight days. Therefore the first post$\mathrm{Na}_{2} \mathrm{CaEDTA}$ day for the patient receiving the shorter course was the day following the fifth day of chelate administration; the apparent break in her cholesterol curve does not indicate a three day period without assays but merely permits the post- $\mathrm{Na}_{2} \mathrm{CaEDTA}$ values of both patients to be plotted on the same graph. Similarly no urinary zinc levels are omitted. Since the maximum value of the standard working curve for zinc was 1,870 $\mu \mathrm{g}$. per L., higher excretions required extrapolation. Excretions above 3,000 $\mu \mathrm{g}$. were not even estimated for this graph.

contrast three of the Africans excreted significantly more zinc and another three excreted more manganese than any of the Americans. The most striking finding, however, involved nickel: Two-thirds of the Africans had urinary concentrations above the maximum American level and there was almost a tenfold difference between the mean concentrations of the two groups.
Table IV indicates the urinary excretion of metals before, during and after the administration of parenteral $\mathrm{Na}_{2} \mathrm{CaEDTA}$ to eight hypercholesterolemic patients. The patient with lead poisoning excreted more than 2,000 $\mu \mathrm{g}$. of lead per $\mathrm{L}$. of urine even during the control period; hence his lead concentrations have been omitted from the calculations. The most striking change during the administration of $\mathrm{Na}_{2} \mathrm{CaEDTA}$ was the prompt tenfold increase in zinc excretion. A smaller effect on cadmium and manganese excretion may well have been present but partially obscured by some control concentrations which were too low to quantitate. Suggestive increases also occurred in lead and vanadium excretion. The increase in cadmium, and perhaps vanadium, seemed to be somewhat delayed. Molybdenum, nickel, silver and tin excretions were apparently not affected. Moreover, no marked change in titanium or chromium excretion was noted. With the possible exception of manganese, the concentrations of urinary metals were returning to their pretreatment range within 24 hours of the time $\mathrm{Na}_{2} \mathrm{CaEDT}$ A administration was stopped. During the control period an average of $1,470 \mathrm{ml}$. of urine was excreted daily in comparison with 1.750 ml. of urine when $\mathrm{Na}_{2} \mathrm{CaEDTA}$ was administered dissolved in $500 \mathrm{ml}$. of 5 per cent glucose in water. Three of the eight patients had some decrease in their mean urine volume while receiving the chelating agent. No significant changes in urinary $\mathrm{pH}$ were observed during $\mathrm{Na}_{2} \mathrm{CaEDTA}$ administration.

Following intravenous $\mathrm{Na}_{2} \mathrm{CaEDTA}$, the level of plasma cholesterol fell in all eight patients, the average decrease being $96 \mathrm{mg}$. per $100 \mathrm{ml}$. plasma and the range being from 37 to $154 \mathrm{mg}$. The changes in plasma cholesterol and the concentrations of urinary metals, including iron, copper, titanium and chromium, have previously been presented as a case report for the nephrotic patient (3). In Figure 2 plasma cholesterol and urinary zinc are plotted on the same time axis for an additional pair of the eight patients, both of whom were atherosclerotic. A fourth patient, the one with pseudobulbar palsy, had cholesterol levels of 256, 273 and $267 \mathrm{mg}$. per $100 \mathrm{ml}$. plasma before he received $\mathrm{Na}_{2} \mathrm{CaEDTA}$. During the first seven days of his 10 day course of $\mathrm{Na}_{2} \mathrm{CaEDTA}$, 
the daily cholesterol levels averaged $193 \mathrm{mg}$. per $100 \mathrm{ml}$. plasma with a minimum of $129 \mathrm{mg}$. Unfortunately no subsequent values were available. Ultracentrifugal studies on this patient's plasma, which were kindly performed by Dr. Robert $\mathrm{H}$. Furman of the Oklahoma Medical Research Foundation, failed to reveal any specific differential effects on the various lipoprotein and Goffman fractions.

\section{COMMENTS}

Our inability to quantify chromium may have been due in part to loss of volatile chromyl chloride during digestion (4). The cause for the unsatisfactory titanium assay is not obvious. Although graphite is frequently contaminated by vanadium, it seems unlikely that such contamination played a major role in the relatively great variability among the 10 replicate vanadium analyses, since the metal was not found in the artificial urine to which it had not been added and since its standard working curve was linear.

The very real problem of contamination has been thoroughly reviewed (5). Wet ashing is the most dubious step. The required reagents are liable to introduce positive contamination; nitric acid is particularly difficult to free from metal impurities. Failure to detect transition or related metals when none was intentionally added to the artifical urine indicated that there was no serious positive contamination. Glass may adsorb metals which can later be eluted; etched beakers were avoided in an effort to minimize adsorbtion. The relatively constant analytic results for a single artificial urine with added metal and the essentially linear standard working curves suggested that negative contamination was not a major problem. With dissimilar urines accuracy would presumably be somewhat less.

As used here 8-hydroxyquinoline has been found to precipitate titanium, molybdenum, iron, cobalt, nickel and zinc quantitatively; thionalide precipitates any remaining manganese, copper, silver, cadmium, tin and lead; and tannic acid completes the precipitation of vanadium and chromium (2). Presumably the combination of these three metal-binding agents would precipitate all the elements in the fourth period from titanium (atomic number 22) to arsenic (atomic number
33). Moreover, the corresponding elements of the fifth and sixth periods would probably be precipitated similarly.

The urine of normal American adults contained measurable amounts of transition and related elements. Excretion of iron, copper, zinc, molybdenum, manganese and cobalt was expected since they are essential trace elements. All but cobalt were found, and presumably its apparent absence was due to insensitivity of our method since Harp and Scoular have reported that the daily renal excretion approximated $5 \mu \mathrm{g}$. (6), an amount which is well below one-twentieth of what we added as an internal standard. On the other hand, titanium, vanadium, chromium, nickel, silver, cadmium, tin and lead have no known biologic function, although each was found in every urine specimen. Tipton and co-workers observed measurable quantities of all these metals, except vanadium, in many adult human tissues from this country (7) ; moreover the other nonessential transition metals which they did not find in tissues ( 7 ) were not observed in the urine.

The age and geographic origin of human beings affect not only the concentrations of cadmium, in their kidneys (8) but also of other metals in many organs (9). The urine of non-Westernized African natives was examined because such people presumably had less exposure to metals. The source and the significance of their excreted nickel is not evident; no obvious means of contamination with this metal was found.

For most of the metals considered here, few excretion studies in man are available. Published data on urinary zinc approximate our findings. In the urine of normal individuals McCance and Widdowson found an average of $0.3 \mathrm{mg}$. of zinc per day; they also found that neither oral nor parenteral administration of zinc increased its renal excretion, although proteinuria was accompanied by a sevenfold increase in zincuria (10). Vallee, Wacker, Bartholomay and Hoch found a mean normal excretion of $440 \mu \mathrm{g}$. of zinc per L. of urine with a standard deviation of $210 \mu \mathrm{g}$.; in contrast for patients with postalcoholic cirrhois of the liver these authors found an excretion of $850 \mu \mathrm{g}$. of zinc per L. of urine (11). For normal individuals Kehoe, Cholak and Story found $27 \mu \mathrm{g}$. of lead, $11 \mu \mathrm{g}$. of tin, less than 10 
$\mu \mathrm{g}$. of manganese, and less than $5 \mu \mathrm{g}$. of silver per L. of urine (12). Smith and Kench found that 10 subjects with no known exposure to cadmium excreted from 2 to $22 \mu \mathrm{g}$. of that metal per $\mathrm{L}$. of urine (13).

The level of cholesterol in human plasma falls following parenteral $\mathrm{Na}_{2} \mathrm{CaEDTA}$ (1). Since this compound is not metabolized in vivo (14), its effect is presumably related in some way to its ability to chelate metals. Except for cobalt, the renal excretion of the entire first transition series of elements from titanium through copper has been investigated following the administration of $\mathrm{Na}_{2} \mathrm{CaEDTA}$. Urinary concentrations of titanium and chromium were only roughly approximated. The concentrations of iron and copper were previously reported for one of the patients (3). $\mathrm{Na}_{2} \mathrm{CaEDTA}$ apparently increased the excretion of manganese, vanadium and iron; however, the most striking effect was the increased excretion of zinc which is not a transition metal. Cadmium and lead, which are also not transition metals, were somewhat affected.

There was no excessive zincuria in our only patient with proteinuria (3) ; however, improvements in the assay technique have required revisions in the previously published nickel and lead excretions before, during and after $\mathrm{Na}_{2} \mathrm{CaEDTA}$. The tabulated nickel concentrations must be revised slightly upward and the lead concentrations must be multiplied by approximately 100 . The very low cadmium concentrations which were reported in the same patient were obtained by using the 2,288.0 $\AA$ cadmium line; his delayed increase in cadmium excretion following $\mathrm{Na}_{2} \mathrm{CaEDTA}$ is striking (3).

\section{SUM MARY}

A method of simultaneously assaying nine trace metals in human urine has been described and the following data obtained by its use :

1. The mean urinary concentrations of zinc, cadmium, manganese, lead, vanadium, molybdenum, nickel, silver and tin were determined for 24 normal adults. Standard errors of the mean and ranges of concentration have been tabulated.

2. Day-to-day variations in the renal excretion of these metals and the changes occurring in acidic, basic, dilute and concentrated urine were measured for one normal adult.
3. The urinary metal was compared for healthy Americans and hospitalized Africans. The most suggestive difference was the greater nickel excretion by the latter.

4. The changes in metal excretion during the administration of disodium calcium ethylenediaminetetraacetate to hypercholesterolemic patients were followed. Marked increases in zinc were universal and lesser increases were observed in cadmium, manganese, lead and vanadium. A fall in plasma cholesterol occurred simultaneously with the increases in urinary metal concentrations.

\section{ACKNOWLEDGMENT}

It is a pleasure to acknowledge the guidance of A. F. Frederickson, Ph.D., formerly Professor of Geology at Washington University, and of John Hower, Ph.D., and Robert Reynolds, Ph.D., who aided in setting up the spectrographic method. John Cary, M.D., and Alexander Kaczmarczyk, Ph.D., performed the chemical concentrations of the urines. André Piraux, M.D., graciously collected the urine samples in Usumbura. The Geology Department of Washington University has generously allowed us free access to their spectrographic laboratory with all of its equipment.

\section{REFERENCES}

1. Perry, H. M., Jr., and Schroeder, H. A. Depression of cholesterol levels in human plasma following ethylenediamine tetraacetate and hydralazine. J. chron. Dis. 1955, 2, 520.

2. Mitchell, R. L., and Scott, R. O. Concentration methods in spectrographic analysis. II. Recovery of trace constituents in plant materials and soil extracts by mixed organic reagents. J. Soc. chem. Ind. (Lond.) 1947, 66, 330.

3. Perry, H. M., Jr., and Schroeder, H. A. Lesions resembling vitamin $\mathrm{B}$ complex deficiency and urinary loss of zinc produced by ethylenediamine tetra-acetate. Amer. J. Med. 1957, 22, 168.

4. Hoffman, J. I., and Lundell, G. E. F. Volatilization of metallic compounds from solutions in perchloric or sulfuric acid. J. Research natl. Bur. Standards 1939, 22, 465.

5. Thiers, R. E. Contamination in trace element analysis and its control in Methods of Biochemical Analysis, D. Glick, Ed. New York, Interscience Publishers, 1957, vol. 2, p. 273.

6. Harp, M. J., and Scoular, F. I. Cobalt metabolism of young college women on self-selected diets. J. Nutr. 1952, 47, 67.

7. Tipton, I. H., Cook, M. J., Steiner, R. L., Foland, J. M., McDaniel, K. K., and Fentress, S. D. Spectrographic analysis of normal human tissue from 
Miami, Florida. Oak Ridge National Laboratory Report, C. F. 57-2-4, February 28, 1957.

8. Perry, H. M., Jr., Tipton, I. H., Schroeder, H. A., Steiner, R. L., and Cook, M. J. The variation in concentration of cadmium and zinc in human kidney and liver with age and geographical origin. Submitted for publication.

9. Perry, H. M., and Tipton, I. H. Unpublished data.

10. McCance, R. A., and Widdowson, E. M. The absorption and excretion of zinc. Biochem. J. 1942, $36,692$.

11. Vallee, B. L., Wacker, W. E. C., Bartholomay, A. F., and Hoch, F. L. Zinc metabolism in hepatic dysfunction. II. Correlation of metabolic patterns with biochemical findings. New Engl. J. Med. 1957, 257, 1055.

12. Kehoe, R. A., Cholak, J., and Story, R. V. A spectrochemical study of the normal ranges of concentration of certain trace metals in biological materials. J. Nutr. 1940, 19, 579.

13. Smith, J. C., and Kench, J. E. Observations on urinary cadmium and protein excretion in man exposed to cadmium oxide dust and fume. Brit. J. industr. Med. 1957, 14, 240.

14. Foreman, H., and Trujillo, T. T. The metabolism of $\mathrm{C}^{14}$ labeled ethylenediaminetetra-acetic acid in human beings. J. Lab. clin. Med. 1954, 43, 566. 